\title{
Tubercular meningitis in children: Clinical, pathological, and radiological profile and factors associated with mortality
}

\author{
Anil V. Israni, Divya A. Dave1, Anirban Mandal, Amitabh Singh², Puneet K. Sahi³, Rashmi Ranjan Das ${ }^{4}$, Arpita Shah ${ }^{5}$ \\ Department of Pediatrics, All India Institute of Medical Sciences, ${ }^{2}$ Department of Pediatrics, Chacha Nehru Bal Chikitsalaya, ${ }^{3}$ Department of Pediatrics, \\ Kalawati Saran Children Hospital, New Delhi, 'Department of Pediatrics, Medical College Baroda and SSG Hospital, ${ }^{5}$ Department of Pathology, \\ Toprani Advanced Lab Systems, Vadodara, Gujarat, ${ }^{4}$ Department of Pediatrics, All India Institute of Medical Sciences, Bhubaneswar, Odisha, India
}

\section{ABSTRACT}

Context: Childhood tuberculosis is a major public health problem in developing countries with tubercular meningitis being a serious complication with high mortality and morbidity. Aim: To study the clinicopathological as well as radiological profile of childhood tuberculous meningitis (TBM) cases. Settings and Design: Prospective, observational study including children $<14$ years of age with TBM admitted in a tertiary care hospital from Western India. Subjects and Methods: TBM was diagnosed based on predefined criteria. Glassgow coma scale (GCS) and intracranial pressure (ICP) was recorded. Staging was done as per British Medical Council Staging System. Mantoux test, chest X-ray, cerebrospinal fluid (CSF) examination, neuroimaging, and other investigations were done to confirm TB. Statistical Analysis Used: STATA software (version 9.o) was used for data analysis. Various risk factors were determined using Chi-square tests, and a $P<0.05$ was considered significant. Results: Forty-seven children were included, of which $11(24.3 \%)$ died. Fever was the most common presenting symptom, and meningismus was the most common sign. Twenty-nine (62\%) children presented with Stage III disease. Stage III disease, low GCS, and raised ICP were predictors of mortality. Findings on neuroimaging or CSF examination did not predict mortality. Conclusions: Childhood TBM presents with nonspecific clinical features. Stage III disease, low GCS, lack of Bacillus Calmette-Guérin vaccination at birth and raised ICP seem to the most important adverse prognostic factors.

Key words: Children, developing country, meningitis, mortality, tuberculosis

\section{Introduction}

India has one of the highest burdens of tuberculosis (TB) globally, accounting for around $20 \%$ of all new TB cases annually. ${ }^{[1]}$ It is estimated that childhood TB constitutes 10-20\% of all TB casesinhighburden countries, ${ }^{[2]}$ accounting for $8-20 \%$ of TB-related deaths. ${ }^{[3]}$ Approximately, $25 \%$ of pediatric TB cases are extrapulmonary, with tuberculous meningitis (TBM) being the most severe form. Worldwide, TBM accounts for majority of the

\section{Address for correspondence:}

Dr. Rashmi Ranjan Das, Department of Pediatrics, All India Institute of Medical Sciences, Bhubaneswar, Odisha, India.

E-mail: rrdas05@gmail.com

\begin{tabular}{|l|l|}
\hline \multicolumn{2}{|c|}{ Access this article online } \\
\hline Quick Response Code: & Website: \\
\hline & www.ruralneuropractice.com \\
\cline { 2 - 2 } & \\
\hline
\end{tabular}

deaths due to TB. ${ }^{[1]}$ A study from South Africa (a high burden country) reported TB to be the commonest cause of childhood meningitis. ${ }^{[4]}$ TBM continues to be an important cause of morbidity (especially neurologic handicap) in children from resource-poor countries. Due to suboptimal performance of the diagnostic tests, TBM diagnosis requires vital clinical information coupled with supportive investigations (biochemical, immunological, and radiological) ${ }_{{ }^{[5]}}$ There have been few studies looking at the clinico-patho-radiological spectrum of this disease in children from India, ${ }^{[6]}$ with fewer addressing the outcome predictors. ${ }^{[7,8]}$ This prospective, observational study was designed to address this issue.

This is an open access article distributed under the terms of the Creative Commons Attribution-NonCommercial-ShareAlike 3.0 License, which allows others to remix, tweak, and build upon the work non-commercially, as long as the author is credited and the new creations are licensed under the identical terms.

For reprints contact: reprints@medknow.com

How to cite this article: Israni AV, Dave DA, Mandal A, Singh A, Sahi PK, Das RR, et al. Tubercular meningitis in children: Clinical, pathological, and radiological profile and factors associated with mortality. J Neurosci Rural Pract 2016;7:400-4. 


\section{Subjects and Methods}

Children of 3 months to 14 years of age with suspected TBM admitted to a tertiary care hospital from Western India were included in the study. TBM was suspected based on following features: Fever and/or a cough for $\geq 2$ weeks, neurological symptoms (irritability, refusal to feed, headache, vomiting, altered sensorium, abnormal movements or seizure) with weight loss or poor weight gain. The diagnosis of TBM was based on the clinical case definition by Doerr et al. [Text box 1]. ${ }^{[9]}$ Ethical clearance was obtained from the Institute Ethics Committee and a written informed consent was taken from either of the parents/legal guardian before enrollment. TBM cases on treatment, those with underlying chronic illness or malignancy or HIV, and those on immunosuppressive therapy were excluded. Demographic data, immunization, contact with TB, and socioeconomic status were recorded. ${ }^{[10]}$ Detailed clinical examination, anthropometry, and the presence of Bacillus Calmette-Guérin (BCG) scar were recorded. ${ }^{[11]}$ The level of consciousness (modified Glassgow coma scale (GCS)), signs of raised intracranial pressure (ICP) and meningeal irritation was noted. Staging of tubercular meningitis was done as per British Medical Council Staging System [Text box 2]. ${ }^{[12]}$

All the recruited children underwent chest X-ray, Mantoux test, and complete hemogram. Additional testing included gastric aspirate for acid-fast Bacilli (AFB), ultrasonography of abdomen and fine needle aspiration cytology from enlarged lymph nodes. A standard

\section{Text box 1: Clinical case definition of tuberculous meningitis devised by Doerr et al.}

Abnormal neurological signs and/or symptoms, and two or more of the following

Discovery of adult source patient with contagious TB who had significant contact with child

Presence of Mantoux (5 tuberculin units) skin test reaction

Cerebrospinal fluid abnormalities without evidence of other infectious cause

Abnormalities on cranial computed tomography consistent with central nervous system TB

TB: Tuberculosis

\section{Text box 2: British Medical Council Staging System for tubercular meningitis}

Stage I: No definite neurological symptoms on admission or in the history before admission, with or without meningismus

Stage II: Signs of meningeal irritations with or without slight clouding of consciousness with focal neurological signs such as cranial nerve palsies or hemiparesis

Stage III: Severe clouding of consciousness or delirium, convulsions and serious neurological signs such as hemiplegia, paraplegia, involuntary movements tuberculin skin test (5 TU) was used and results read after $72 \mathrm{~h}$ (positive: Induration of $\geq 10 \mathrm{~mm}$; HIV and severe malnutrition: $\geq 5 \mathrm{~mm}$ was considered positive). Cerebrospinal fluid (CSF) analysis was done including the presence of AFB. All the children underwent neuroimaging (plain and contrast enhanced computed tomography or magnetic resonance imaging [MRI]). HIV testing was done where appropriate.

The data were entered into Microsoft excel sheet and analyzed using Stata 9.0 software (STATA Corp, College Station, TX, USA). Descriptive statistics was used along with analysis of risk factors by using Chi-square test or Fisher's test. A $P<0.05$ was considered statistically significant.

\section{Results}

Of 50 TBM cases, 47 met the eligibility criteria and were included. The baseline characteristics and clinical features are presented in Table 1. Majority of children were from lower socioeconomic status (85\%) and were malnourished $(76.6 \%)$. Fever, altered sensorium, and seizure were the most common symptoms. Contact history of $\mathrm{TB}$ was positive in $49 \%$ cases, $55 \%$ of children were BCG vaccinated, Mantoux test was positive in $25 \%$ [Table 1]. CSF examination could be done in 45 children $(10 \%$ had opalescent appearance, no xanthochromia or hemorrhage or cobweb formation was noted). Chest X-ray abnormality was found in 38\% [Table 2]. Common abnormalities noted on neuroimaging were: Communicating hydrocephalus (70\%), meningeal enhancement $(64 \%)$, and infarction (45\%) [Table 2]. Meningeal enhancement was most commonly observed over the basal cisterns (47\%) and cerebral cortex (43\%). Infarction was most common in basal ganglion (67\%) followed by cortex (41\%).

The mortality rate was $23.4 \%$ (11 of 47 died). Various risk factors associated with mortality or poor outcome were analyzed. Stage III disease, low GCS, and raised ICP were associated with increased mortality [Table 3], whereas biochemical and cytological parameters did not affect the outcome (data not shown). A significantly increased risk of mortality was found in children who were not vaccinated with BCG at birth.

\section{Discussion}

We summarized the clinical, pathological, and radiological features of TBM and investigated characteristics associated with mortality. Children with TBM had nonspecific clinical pictures, boys were commonly affected, Mantoux positivity was in $25 \%$, chest X-ray 
Table 1: Baseline and clinical characteristics of children with tubercular meningitis

\begin{tabular}{|c|c|}
\hline Characteristics & $n(\%)$ \\
\hline Male & $28(59.6)$ \\
\hline \multicolumn{2}{|l|}{ Age distribution (years) } \\
\hline $0-3$ & $28(59.6)$ \\
\hline $3-5$ & $8(17)$ \\
\hline$>5$ & $11(23.4)$ \\
\hline \multicolumn{2}{|l|}{ Socioeconomic status } \\
\hline Upper-middle & $1(2.1)$ \\
\hline Lower-middle & $6(12.8)$ \\
\hline Lower & $40(85.1)$ \\
\hline Positive history of contact with TB & $23(49)$ \\
\hline BCG vaccination & $26(55.3)$ \\
\hline \multicolumn{2}{|l|}{ Nutritional status } \\
\hline Normal & $11(23.4)$ \\
\hline Malnutrition (mild to moderate) & $31(66)$ \\
\hline Malnutrition (severe) & $5(10.6)$ \\
\hline \multicolumn{2}{|l|}{ Symptoms } \\
\hline Fever & $34(72.3)$ \\
\hline Altered sensorium & $27(57.4)$ \\
\hline Seizure/abnormal movements & $23(48.9)$ \\
\hline Abnormal posturing & $13(27.7)$ \\
\hline Headache & $12(25.5)$ \\
\hline Irritability & $9(19.2)$ \\
\hline Vomiting & $8(17)$ \\
\hline Refusal of feeds & $4(8.5)$ \\
\hline Limping & $2(4.2)$ \\
\hline Cough & $1(2.1)$ \\
\hline Paucity of movement & $1(2.1)$ \\
\hline Increasing head size & $1(2.1)$ \\
\hline \multicolumn{2}{|l|}{ Signs } \\
\hline Meningeal irritation & $31(66)$ \\
\hline Hemiparesis & $7(14.9)$ \\
\hline Cranial nerve palsy & $6(12.8)$ \\
\hline Quadriparesis & $4(8.5)$ \\
\hline Abnormal movements & $3(6.4)$ \\
\hline \multicolumn{2}{|l|}{ Level of consciousness (GCS) $(n=41)$} \\
\hline$<7$ & $15(36.6)$ \\
\hline $7-10$ & $9(22)$ \\
\hline$>10$ & $17(41.4)$ \\
\hline Raised ICP & $31(66)$ \\
\hline \multicolumn{2}{|l|}{ Stage of TBM } \\
\hline I & 7 (14.9) \\
\hline II & $11(23.4)$ \\
\hline III & $29(61.7)$ \\
\hline
\end{tabular}

ICP: Intracranial pressure, TB: Tuberculosis, BCG: Bacillus Calmette-Guérin, TBM: Tuberculous meningitis, GCS: Glasgow coma scale

compatible with TB in 38\% cases, and communicating hydrocephalus was the most common neuroimaging finding. Stage III disease, low GCS, and raised ICP were associated with increased mortality.

The male preponderance (1.5:1) observed in the present study was consistent with earlier pediatric studies from India. ${ }^{[6,7]}$ Most common age group affected was $<3$ years $(60 \%)$ followed by 3-6 years $(16 \%)$. Globally, children $<5$ years of age have been found to be most vulnerable. ${ }^{[13-15]}$ Contact with TB could be elicited in about $50 \%$ of children in present study, this figure has been reported between 33\% and 69\% in various studies. ${ }^{[6,14,15]}$ This emphasizes the importance of eliciting contact history and family screening for TB in suspected cases of TBM. Despite being almost universally recommended and potentially highly effective, screening to provide preventive therapy for eligible contacts is still rarely implemented in TB endemic communities. ${ }^{[16]}$

Though BCG vaccination is included under the universal immunization coverage, only $55 \%$ of children were vaccinated in the present study. As BCG vaccination protects against severe froms of TB (e.g., TBM, and disseminated or milliary $\mathrm{TB}$ ), a lower vaccination coverage could explain a higher prevalence of severe from of TB (e.g., TBM) in the present study ${ }^{[17]}$ Studies from India and Western countries have clearly documented the effect of BCG vaccine in reducing mortality from TBM. ${ }^{[17-19]}$ In a systematic review and metanalysis for treatment outcome of TBM in children, the authors emphasized on the role of BCG vaccination as an invaluable preventive measure for TBM. ${ }^{[19]}$ Our study demonstrated mantoux positivity only at mere $25 \%$ in children with TBM. TBM being an extra-pulmonary disease, a low rate of positive mantoux reaction in children with TBM is expected, though the rates vary widely. ${ }^{[6-8,14]}$

Most of the children (62\%) in this study were detected at an advanced stage (Stage III). Advanced stage has been found to be the single most important factor associated with poor outcome, ${ }^{[14]}$ and the same has been echoed in our study. Mortality was nil in Stage I or Stage II disease but was 38\% in Stage III disease. Cranial nerve palsy has been recognized as an important clinical indicator in differentiating TBM from pyogenic meningitis. ${ }^{[20]}$ In this study, $13 \%$ children present with cranial nerve palsy. Around $54 \%$ of children having GCS $<7$ died, and GCS was found to be one of the predictors of mortality in the present study. This has been reported in previous Indian studies. ${ }^{[8]}$ Around $39 \%$ of children with raised ICP died, and this was found to be another predictors of mortality. Previous studies also report similar observation. ${ }^{[8]}$

Abnormal chest X-ray was observed in $38 \%$ of patients in this study. A previous study found this figure as $44 \%{ }^{[21]}$ None of the radiological findings (chest X-ray, computed tomography scan, or MRI brain) predicted the mortality. While looking at the CSF findings, patients dying of TBM had higher mean CSF protein values and also CSF lymphocytic pleocytosis compared to those who survived. 
The overall mortality in the present study was $23.4 \%$. A previous systematic review reported this figure as $19.3 \% \cdot{ }^{[22]}$ However, in 10 years comparative retrospective analysis, one study reported this figure as $8 \%$ in children with TBM. ${ }^{[23]}$

The strengths of the present study are prospective enrollment of children and careful documentation using

Table 2: Laboratory and neuroimaging findings in children with tuberculous meningitis

\begin{tabular}{lc}
\hline Investigations & $\boldsymbol{n}(\%)$ \\
\hline Mantoux positive & $12(25)$ \\
Abnormal chest X-ray & $18(38)$ \\
HIV positive & $2(4.3)$ \\
CSF protein $(n=45)(\mathrm{mg} / \mathrm{dl})$ & \\
$\quad<40$ & $4(8.9)$ \\
$40-400$ & $40(88.9)$ \\
$>400$ & $1(2.2)$ \\
CSF glucose $(n=45)(\mathrm{mg} / \mathrm{dl})$ & \\
$<20$ & $12(26.7)$ \\
$20-60$ & $25(55.6)$ \\
$>60$ & $8(17.7)$ \\
CSF total cells $(n=45) / \mathrm{mm}^{3}$ & \\
$<10$ & $12(26.7)$ \\
10-100 & $10(22.2)$ \\
101-400 & $18(40)$ \\
$>400$ & $5(11.1)$ \\
CSF lymphocyte percentage $(n=45)$ & \\
$<20$ & $3(6.6)$ \\
$20-80$ & $21(46.7)$ \\
$>80$ & $21(46.7)$ \\
Abnormality on neuroimaging & \\
Meningeal enhancement & $30(63.8)$ \\
Hydrocephalus & $33(70.2)$ \\
Periventricular edema & $21(44.7)$ \\
Infarcts & $27(57.4)$ \\
Tuberculoma & $5(10.6)$ \\
\hline CSF: Cerebrospinal fluid & \\
&
\end{tabular}

a standardized predesigned data collection form. The case definition of TBM was also predefined, and the same was also used in a previous study from India, thus making it easier to compare the results. The limitations are: Being a single center study conducted at a tertiary care referral hospital, referral bias cannot be ruled out; TB culture and nucleic acid amplification tests (Genexpert) were not conducted on the CSF specimen; treatment outcome and follow-up of the patients to look for neurological sequelae could not be done.

The incidence of TBM indicates the annual risk of infection, and a robust surveillance system for documenting the occurrence of TBM in young children can improve estimates and monitoring of the TB burden and TB-related deaths in children. ${ }^{[2]}$ Newer and easier scoring systems need to be devised in the lights of ever increasing knowledge for better prediction of outcome of this dreaded disease. ${ }^{[25]}$ Furthermore, the survivors of tubercular meningitis are at a risk of long-term neurological sequelae ranging from residual paresis to subtle neurological deficit in the form of poor scholastic performance or even behavioral abnormalities. This mandates a close and regular follow-up of these children for early intervention.

\section{Conclusion}

Tubercular meningitis continues to be associated with high rate mortality in children of countries with high burden of TB. Even with the advancement of scientific knowledge and technologies, including new techniques of laboratory and imaging diagnostic aid, very little prediction can be made regarding the prognosis of children with this dreaded disease. Our study highlighted few important predictors associated with mortality in

Table 3: Factors associated with mortality from tubercular meningitis in children

\begin{tabular}{|c|c|c|c|c|c|}
\hline \multirow[t]{2}{*}{ Risk factors } & \multirow[t]{2}{*}{ Categories } & \multicolumn{2}{|c|}{ Outcome } & \multirow[t]{2}{*}{ OR (95\% Cl) } & \multirow[t]{2}{*}{$P$} \\
\hline & & Survived & Expired & & \\
\hline Age & $\geq 5$ years & 8 & 3 & $1.31(0.28-6.14)$ & 0.73 \\
\hline Gender & Male & 21 & 7 & $1.25(0.31-5.05)$ & 0.75 \\
\hline History of contact with TB & Present & 17 & 6 & $3.88(0.69-21.7)$ & 0.1 \\
\hline Socioeconomic class & Lower class & 29 & 11 & - & 0.11 \\
\hline Nutritional status & Severe to very severe PEM & 6 & 4 & $1.5(0.33-6.82)$ & 0.59 \\
\hline GCS & $<7$ & 7 & 8 & $28.6(3.04-268.77)$ & $<0.001$ \\
\hline BCG vaccination & Unvaccinated & 13 & 8 & $4.72(1.06-20.96)$ & 0.03 \\
\hline Mantoux test & Negative & 29 & 6 & $1.03(0.18-5.98)$ & 0.97 \\
\hline Stage of TBM & III & 18 & 11 & - & 0.002 \\
\hline Raised ICP & Present & 17 & 11 & - & 0.001 \\
\hline Abnormality in chest X-ray & Present & 13 & 5 & $3.33(0.69-16.16)$ & 0.12 \\
\hline Hydrocephalus & Present & 22 & 9 & $2.86(0.54-15.25)$ & 0.21 \\
\hline Brain infarction & Present & 20 & 7 & $1.58(0.39-6.28)$ & 0.73 \\
\hline
\end{tabular}

OR: Odds ratio, Cl: Confidence interval, ICP: Intracranial pressure, TBM: Tuberculous meningitis, GCS: Glassgow coma scale, TB: Tuberculosis, PEM: Protein-energy malnutrition 
this age group coupled with a reemphasis on need for early diagnosis, though the challenge remains to devise composite index systems in predicting outcome in TBM in future years.

\section{Financial support and sponsorship \\ Nil.}

\section{Conflicts of interest}

There are no conflicts of interest.

\section{References}

1. World Health Organization (WHO). Global Tuberculosis Report 2013. Geneva: WHO; 2013. Available from: http://www.apps.who.int/iris/ bitstream/10665/91355/1/9789241564656_eng.pdf. [Last accessed on 2015 Dec 15].

2. Marais BJ, Hesseling AC, Gie RP, Schaaf HS, Beyers N. The burden of childhood tuberculosis and the accuracy of community-based surveillance data. Int J Tuberc Lung Dis 2006;10:259-63.

3. Jain SK, Ordonez A, Kinikar A, Gupte N, Thakar M, Mave V, et al. Pediatric tuberculosis in young children in India: A prospective study. Biomed Res Int 2013;2013:783698.

4. Wolzak NK, Cooke ML, Orth H, van Toorn R. The changing profile of pediatric meningitis at a referral centre in Cape Town, South Africa. J Trop Pediatr 2012;58:491-5.

5. van Toorn R, Solomons R. Update on the diagnosis and management of tuberculous meningitis in children. Semin Pediatr Neurol 2014;21:12-8.

6. Thilothammal N, Krishnamurthy PV, Banu K, Ratnam SR. Tuberculous meningitis in children - Clinical profile, mortality and morbidity of bacteriologically confirmed cases. Indian Pediatr 1995;32:641-7.

7. Ramzan A, Nayil K, Asimi R, Wani A, Makhdoomi R, Jain A. Childhood tubercular meningitis: An institutional experience and analysis of predictors of outcome. Pediatr Neurol 2013;48:30-5.

8. Karande S, Gupta V, Kulkarni M, Joshi A. Prognostic clinical variables in childhood tuberculous meningitis: An experience from Mumbai, India. Neurol India 2005;53:191-5.

9. Doerr CA, Starke JR, Ong LT. Clinical and public health aspects of tuberculous meningitis in children. J Pediatr 1995;127:27-33.

10. Kumar N, Shekhar C, Kumar P, Kundu AS. Kuppuswamy's socioeconomic status scale-updating for 2007. Indian J Pediatr 2007;74:1131-2.

11. Khadilkar VV, Khadilkar AV, Choudhury P, Agarwal KN, Ugra D, Shah NK. IAP growth monitoring guidelines for children from birth to 18 years. Indian Pediatr 2007;44:187-97.

12. British Medical Research Council. Streptomycin treatment of tuberculous meningitis. Br Med J 1948;1:582-97.

13. Humphries MJ, Teoh R, Lau J, Gabriel M. Factors of prognostic significance in Chinese children with tuberculous meningitis. Tubercle 1990;71:161-8.

14. van Well GT, Paes BF, Terwee CB, Springer P, Roord JJ, Donald PR, et al. Twenty years of pediatric tuberculous meningitis: A retrospective cohort study in the western cape of South Africa. Pediatrics 2009;123:e1-8.

15. Lee LV. Neurotuberculosis among Filipino children: An 11 years experience at the Philippine Children's Medical Center. Brain Dev 2000;22:469-74.

16. Hill PC, Rutherford ME, Audas R, van Crevel R, Graham SM. Closing the policy-practice gap in the management of child contacts of tuberculosis cases in developing countries. PLoS Med 2011;8:e1001105.

17. Kelekçi S, Karabel M, Karabel D, Hamidi C, Hosoglu S, Gürkan MF, et al. Bacillus Calmette-Guérin is a preventive factor in mortality of childhood tuberculous meningitis. Int J Infect Dis 2014;21:1-4.

18. Kumar R, Dwivedi A, Kumar P, Kohli N. Tuberculous meningitis in BCG vaccinated and unvaccinated children. J Neurol Neurosurg Psychiatry 2005;76:1550-4.

19. Chiang SS, Khan FA, Milstein MB, Tolman AW, Benedetti A, Starke JR, et al. Treatment outcomes of childhood tuberculous meningitis: A systematic review and meta-analysis. Lancet Infect Dis 2014;14:947-57.

20. Moghtaderi A, Alavi-Naini R, Rashki S. Cranial nerve palsy as a factor to differentiate tuberculous meningitis from acute bacterial meningitis. Acta Med Iran 2013;51:113-8.

21. Solomons RS, Goussard P, Visser DH, Marais BJ, Gie RP, Schoeman JF, et al. Chest radiograph findings in children with tuberculous meningitis. Int J Tuberc Lung Dis 2015;19:200-4.

22. Graham SM, Donald PR. Death and disability: The outcomes of tuberculous meningitis. Lancet Infect Dis 2014;14:902-4.

23. Miftode EG, Dorneanu OS, Leca DA, Juganariu G, Teodor A, Hurmuzache $\mathrm{M}$, et al. Tuberculous meningitis in children and adults: A 10-year retrospective comparative analysis. PLoS One 2015;10:e 0133477.

24. Styblo K, Sutherland I. The epidemiology of tuberculosis in children. Bull Int Union Tuberc 1982;57:133-9.

25. Alarcón F, Moreira J, Rivera J, Salinas R, Dueñas G, Van den Ende J. Tuberculous meningitis: Do modern diagnostic tools offer better prognosis prediction? Indian J Tuberc 2013;60:5-14. 